\title{
Dreaming of a Brighter Future: Anticipating Happiness Instills Meaning in Life
}

\author{
Wijnand A. P. van Tilburg ${ }^{1}$ (D) Eric R. $\operatorname{Igou}^{2}$
}

Published online: 16 January 2018

(C) The Author(s) 2018. This article is an open access publication

\begin{abstract}
We theorized and tested that people's predictions of their future as brighter than the present fulfill an important purpose: they give a sense of meaning to life. We systematically tested this existentialist hypothesis by adopting a self-regulatory approach. Study 1 indicates that envisioning a happier future helps people to find meaning in everyday life behaviors, provided that these are perceived to be instrumental for the pursuit of happiness. Consistently, Study 2 shows that envisioning such increases in future happiness is particularly employed by those who are prone to seek meaning in life. Finally, Study 3 reveals that after people envision a brighter future their perceived meaning in life increases, and it does so especially for those prone to search for meaning in life. Together, these studies suggest that imagining future happiness in part serves the function of perceiving life as meaningful. This research is novel, and builds on and contributes to the literature on meaning making, happiness, well-being, and affective forecasting.
\end{abstract}

Keywords Happiness · Meaning $\cdot$ Existential psychology $\cdot$ Self-regulation $\cdot$ Affective forecasting

\section{Introduction}

Humans are skilled in anticipating the future and adjusting their behavior accordingly. Nonetheless, people often make incorrect predictions, whether this is due to misleading heuristics (e.g. Kahneman et al. 1982) or by unrealistic optimism about the realization of one's goals (e.g. Radcliffe and Klein 2002; Weinstein 1980). Research documents that errors in people's forecasting of affective states are common (e.g. Wilson et al. 2000;

Wijnand A. P. van Tilburg

Wijnand.van_Tilburg@kcl.ac.uk

1 Department of Psychology, Institute of Psychiatry, Psychology, and Neuroscience, King's College London, Room 2.12, Addison House, Guy's Campus, London, UK

2 Department of Psychology, University of Limerick, Limerick, Co. Limerick, Republic of Ireland 
Loewenstein and Schkade 1999; Wilson and Gilbert 2003). For example, people typically overestimate the duration and intensity of events, such as winning the lottery, a break-up, or failing to secure tenure (e.g. Brickman et al. 1978; Buehler and McFarland 2001; Gilbert et al. 1998; Schkade and Kahneman 1998). In addition, people are not only systematically biased when it comes to themselves, but they can be just as imprecise or even worse when it comes to predicting other people's affective states (e.g. Igou 2008). Related research on unrealistic optimism consistently indicates that people paint overly bright pictures of their future encounters, and they are inclined to underestimate the likelihood that bad things will happen to them, especially compared to when making the same estimates for others (e.g. Weinstein 1980; Weinstein and Lachendro 1982).

Several reasons have been proposed and tested why people tend to be overly optimistic about future happiness, including the disregard of how contextual factors interfere with affective states (e.g. Wilson et al. 2000), ignorance regarding coping strategies that people employ when dealing with negative events (e.g. Gilbert et al. 1998; Igou 2008), lay theories about the progression of affect (e.g. Igou 2004), and self-enhancement (Heller et al. 2011). Essentially, although humans may have the exceptional ability to envision the future, such forecasts often come with errors and biases (e.g. Wilson and Gilbert 2003).

\section{Dreaming of a Bright Future: Anticipated Happiness}

One striking domain of forecasting errors concerns people's biased anticipation of their own overall well-being, life satisfaction, and, especially relevant to the present investigation, happiness (e.g. Wilson et al. 2000). Happiness is an evaluative state that offers key insight into the welfare of people; it can be regarded as the one of the most important human motives (e.g. Seligman et al. 2005; Peterson et al. 2005). Indeed, being happy is associated with a host of important individual and social factors, including longevity (e.g. Deeg and Van Zonneveld 1989), altruism (e.g. Post 2005), and creative processes (e.g. Pannells and Claxton 2008), just to name a few. Moreover, people ascribe high importance to subjective well-being as a general goal in life (e.g. Diener 2000), and this goal shapes self-regulatory behavior accordingly (e.g. Larsen and Prizmic 2004; Ryan and Deci 2000). People strive in the hope for improvement in a range of areas, and one of these desired improvements is associated with a central desirable psychological state: happiness.

The affective forecasting literature has documented people's anticipated and overestimated affective responses to specific negative and positive events (see Wilson and Gilbert 2003). Moreover, people generally anticipate becoming happier in the future (e.g. Heller et al. 2011; Robinson and Ryff 1999). It is, of course, pleasant to think that the future will be brighter than the present, but research shows that changes in affective states are usually much less durable than people believe (e.g. Wilson and Gilbert 2003; Igou 2004). Moreover, major and lasting changes in happiness over the course of life are rather the exception than the norm (Brickman and Campbell 1971; Brickman et al. 1978; Diener and Diener 1996; Diener et al. 2006). Although happiness varies with age-typically yielding a U-shaped relationship (Blanchflower and Oswald 2004) - this association is fairly small, with minor changes materializing over the course of a decade (e.g. Mroczek and Kolarz 1998, p. 1341). Unfortunately, people adapt more easily to new positive circumstances, such as winning the lottery or living in sunny Southern California, than expected (Schkade and Kahneman 1998), and any increase in happiness is often much shorter and less imperishable than people believe (Brickman and Campbell 1971; Diener et al. 2006). In sum, 
people seem to hold the belief that they will become happier in the future; yet, there is little evidence to suggest that, on average, people become happier over the course of a lifetime.

\section{The Existential Benefit of Anticipated Happiness}

The finding that, on average, happiness does not change much over a lifetime begets the question why people nonetheless envision a brighter future for themselves. This happiness bias in forecasting may, in part, be rooted in particular cognitive processes (e.g. Wilson and Gilbert 2003; Igou 2004); however, we focus here on a motivational process. Specifically, we pose that envisioning a brighter future is partly motivated by a valuable existential benefit: It serves as a vehicle to perceive one's life as meaningful.

\subsection{The Quest for Meaning}

The psychological study of 'meaning' has gained much attention in recent years. Psychologists have studied the benefits associated with perceiving life as meaningful (e.g. Steger et al. 2006), and the psychological responses to threats to such perceptions (e.g. Greenberg et al. 1986, 2004; Proulx and Heine 2006). Perceiving life as meaningful reflects that one can make sense of life, at least in terms of explaining it according to a coherent frame of reference such as a cultural worldview, political ideology, or religion (Greenberg et al. 2004; Heine et al. 2006).

Importantly, perceiving life as meaningful is conceptually and experientially different from simply living a happy life, although this may certainly co-occur. As extensively discussed and tested by Baumeister et al. (2013; see also Steger et al. 2006), differences between the constructs include that happiness seems to be largely rooted in biological factors, whereas meaningfulness seems to originate more from cultural factors. Moreover, meaningfulness and happiness correlate in opposite ways with constructs such as prosocial orientations. Indeed, Baumeister and colleagues establish the notion that people may sometimes lead an unhappy but meaningful life, characterized by extensive worry and contemplation, as opposed to people who consider life to be happy but meaningless, perhaps typified by a carefree and selfish lifestyle. Thus, happiness and meaning in life are correlated but conceptually and experientially different phenomena. More formally, according to the configurative perspective by Shmotkin and Shrira (2013) well-being and meaning in life are related, but serve distinct regulatory processes where these factors conjointly allow individuals to be resilient in the face of adverse life events or threats.

The pursuit and maintenance of meaning in life have pervasive effects on information processing and behavior, such as seeking patterns and structure (Proulx and Heine 2006), derogating outgroups (Van Tilburg and Igou 2011b), eating and drinking behavior (e.g. Moynihan et al. 2015; Wisman 2006), and bolstering meaning-laden worldviews or ideologies (e.g. Maher et al. 2013; Greenberg et al. 2004; Van Tilburg and Igou 2011a). Perceiving life as meaningful is a valuable asset to human functioning and correlates with desirable qualities such as life satisfaction, happiness, and work-enjoyment (e.g. Bonebright et al. 2000), suggesting that at least on average meaning in life and affect are positively associated.

In recent years, the link between meaning and positive affect in general received increasing empirical attention. Experimental and correlational work by King et al. (2006), for example, indicated that people who possess dispositional high positive affect or were 
induced with positive affect in turn reported greater perceived meaning in life. Follow-up research (Hicks et al. 2010) further confirmed that everyday life positive affect is a key predictor of perceived meaning in life. We build on these earlier findings by recognizing the connection between perceptions of meaning and the experience of forms of positive affect, and in particular happiness. Different from this existing literature, however, we extended this investigation into the domain of forecasted happiness. Thus, we examined the link between meaning and anticipated happiness to shed light on the role that forecasting happiness plays for meaning-regulation in the present.

\subsection{Meaning and Anticipated Happiness}

How and why might anticipated happiness relate to people's quest for meaning? As happiness is an overarching goal in life for many, anticipating happiness provides meaning for subgoals and behaviors that are instrumental for this overarching goal (e.g. Van Tilburg and Igou 2013a). Specifically, adopting the belief that life will bring happiness makes one's behaviors that are believed to facilitate this future state seem meaningful. Thus, envisioning a brighter, happier future enables people to identify and capitalize on the meaning of their everyday life behaviors. If anticipated happiness serves as a tool for affirming the meaningfulness of one's behaviors, then in particular the people who search for meaning, compared to their less meaning searching counterparts, should envision relatively large happiness gains in the future in their attempt to imbue their behaviors with meaning.

The hypothesis that an overarching goal, such as the acquisition of happiness, lends meaning to behaviors is novel and broadly consistent with recent findings on the self-regulatory mechanisms that underlie meaning-appraisals. Based on research on the structure of goals and motivation (e.g. Heckhausen and Heckhausen 2008; Kruglanski et al. 2002), and self-determination literature (e.g. Deci and Ryan 2000; Ryan and Deci 2004), Van Tilburg and Igou (2013a) found that when a particular behavior (e.g. training for a marathon) becomes associated with an overarching goal (e.g. celebrating one's victory over cancer), then the behavior is perceived to be more meaningful compared to when an overarching goal is absent or not salient. In addition, research suggests that those suffering from distress and dissatisfaction are more inclined to forecast a happier future (Busseri et al. 2008), and indicators of distress and dissatisfaction in turn correlate positively with the search for meaning (Steger et al. 2006). Furthermore, research on individual differences suggests that those who are optimistic about their future tend to have a greater sense of meaning in life (Steger et al. 2006). Moreover, research by Kim et al. (2014) indicates that meaning is typically associated with a focus on long-term benefits as opposed to the near future. Taken together, these findings are consistent with the idea that anticipating happiness serves, in part, as a self-regulatory goal to obtain a sense of meaning in life.

\subsection{The Roles of Meaning Search and Behavioral Instrumentality}

Our general assumption holds that people make positive happiness forecasts in part to harness its proposed benefits for attaining a sense of meaning in life. This existential perspective on anticipated happiness rests on basic self-regulatory assumptions. The existential usefulness of anticipating happiness is conditional on the degree to which people search for meaning in life, with forecasting a bright future being particularly useful when people are high (vs. low) in search of meaning in life. Further, the effects of anticipated happiness and meaning in life depend on the instrumentality of means available to pursue happiness. 
Anticipated increases in happiness are likely to lend meaning particularly to those behaviors that seem instrumental for a happier future (Van Tilburg and Igou 2011b, 2013b, 2017). In contrast, the perceived meaningfulness of behaviors that are not instrumental for this happier future is likely to remain unaffected, or even diminish, when people envision future happiness. For example, anticipating a happier future may help people to find greater meaning in the behavior of making friends, assuming that people generally consider it to be a source of happiness. However, anticipating a happier future may not enhance the perceived meaningfulness of watching soaps on television, assuming that people generally consider it to be a less potent source of happiness.

Overall, we propose that anticipated increases in happiness affirm the meaningfulness of behaviors that are instrumental for the pursuit of happiness, but not those that are relatively non-instrumental for the pursuit of happiness. In fact, it might well be that anticipating future happiness further reduces the perceived meaning attributed to behaviors low in instrumentality towards this envisioned happier future. King and colleagues (2006) found that positive affect increased the differentiation between tasks seen as more or less meaningful (see also Trope et al. 2006). In particular, they found that positive affect enhanced the perceived meaningfulness of meaningful tasks, but undermined the perceived meaningfulness of tasks that were meaningless to start with. According to King and colleagues (2006), this differentiation might reflect that positive affect "may be thought of as a readiness or preparedness for meaningful experience" (p. 189), which, consistent with our own work on the topic (Van Tilburg and Igou 2013a) may make people differentiate more between the usefulness of particular tasks for the pursuit of goals (here: future happiness). Thus, we anticipated that anticipated future happiness may not only increase the perceived meaningfulness of behaviors that are highly instrumental towards this happier future, but may simultaneously decrease the perceived meaningfulness of behaviors that contribute little towards this happier future.

\section{Study Overview}

In Study 1, we examined experimentally whether imagining an increase in future happiness enhanced the meaningfulness of behaviors in the present. Next, we tested in Study 2 whether anticipated happiness was more pronounced for people high (vs. low) in search for meaning in life to test the motivational process underlying these forecasts. Study 3 integrated these prior approaches by testing whether the meaning gained from experimentally induced anticipated happiness were more pronounced for people high (vs. low) in search for meaning in life.

\subsection{Study 1: Anticipated Happiness Imbues Behavior with Meaning}

In Study 1, we tested if anticipated happiness yields an existential benefit by bestowing meaning to behaviors in the present. Specifically, if anticipated happiness has this proposed existential function, then meaningfulness would be attributed to behaviors that serve future happiness compared to behaviors that do not serve this goal. In order to test this prediction, we manipulated the degree of anticipated happiness and then measured evaluations of the meaningfulness of behaviors. Anticipated happiness was manipulated by having participants either focus on happiness in the future or on the future without explicit reference to happiness (control condition). Given that this procedure would make future happiness 
more salient in one than in the other condition, we predicted increases in anticipated happiness in the experimental versus the control condition. Importantly, based on our assumption that happiness forecasts yield an existential benefit, we further expected that a focus on future happiness would increase the meaningfulness of one's behavior.

If anticipated happiness has the hypothesized existential benefit of identifying meaning in one's behavior, then this likely only applies to behaviors that are perceived to be instrumental for happiness and not to behaviors that are of little perceived instrumentality for obtaining future happiness. We thus included an additional variation to test for the benefit of anticipated happiness. Specifically, we contrasted three clusters of four behaviors perceived as generally high versus moderate versus low in their instrumentality for contributing to a happy future. We predicted that the future happiness focus would increase the perceived meaningfulness of behaviors that serve the happiness goal, but that it would decrease the perceived meaningfulness of the less instrumental behaviors.

\subsubsection{Method}

4.1.1.1 Participants and Design Fifty students (13 men, 37 women; $M_{\text {age }}=19.22$, $S D=1.49$ ) took part in a 2 (future focus: happier vs. control) $\times 3$ (behavior cluster: high instrumentality vs. neutral vs. low instrumentality) mixed subjects design with the future focus variation as between-subjects factor and the behavior cluster as within subjects factor. Post-hoc power analysis for this $2 \times 3$ mixed design indicated a power of $(1-\beta)=.91$ for detecting effects of $\eta^{2}=.10$, assuming a two-tailed $\alpha$ of .05 , and a correlation between repeated measures of $r=-.25$.

4.1.1.2 Materials and Procedure Students were approached on campus and asked for their willingness to take part in a short paper-and-pencil study. Upon agreement, participants gave their informed consent and reported demographic information. Participants in the happier future focus condition were then requested to jot down three happy things that they anticipated in the future; participants in the control condition instead listed future things without being explicitly instructed that these related to happiness. Thus, although participants focused on the future in both conditions, only in the happier future focus condition they explicitly focused on potentially becoming happier. We then instructed participants to "Consider the following list of behaviors and consider how meaningful you think they are. Please rank these behaviors in the order from 1 to 12, with 1 being the most meaningful behavior and 12 being the least meaningful". We conducted two pilot studies in order to test for the effectiveness of the experimental manipulation and the instrumentality associated with each of the 12 behaviors.

4.1.1.3 Pilot Study 1: Anticipation of Greater Happiness A pilot study among thirtynine students confirmed that those who focused on a happier future anticipated happiness to a greater extent $(M=5.72, S D=1.02)$ compared to the control condition $(M=5.00$, $S D=1.12), F(1,36)=4.28, p=.05, \eta^{2}=.11$, rated on the item "To what extent do you think that you will become happier in the future?" $(1=$ not at all, $7=$ very much $)$. The manipulation was thus effective.

4.1.1.4 Pilot Study 2: Behaviors as Source of Happiness We generated 12 behaviors as part of a lab meeting discussion. In a pilot study, fifteen students then ranked these twelve behaviors The results indicated that the four most instrumental behaviors for future hap- 


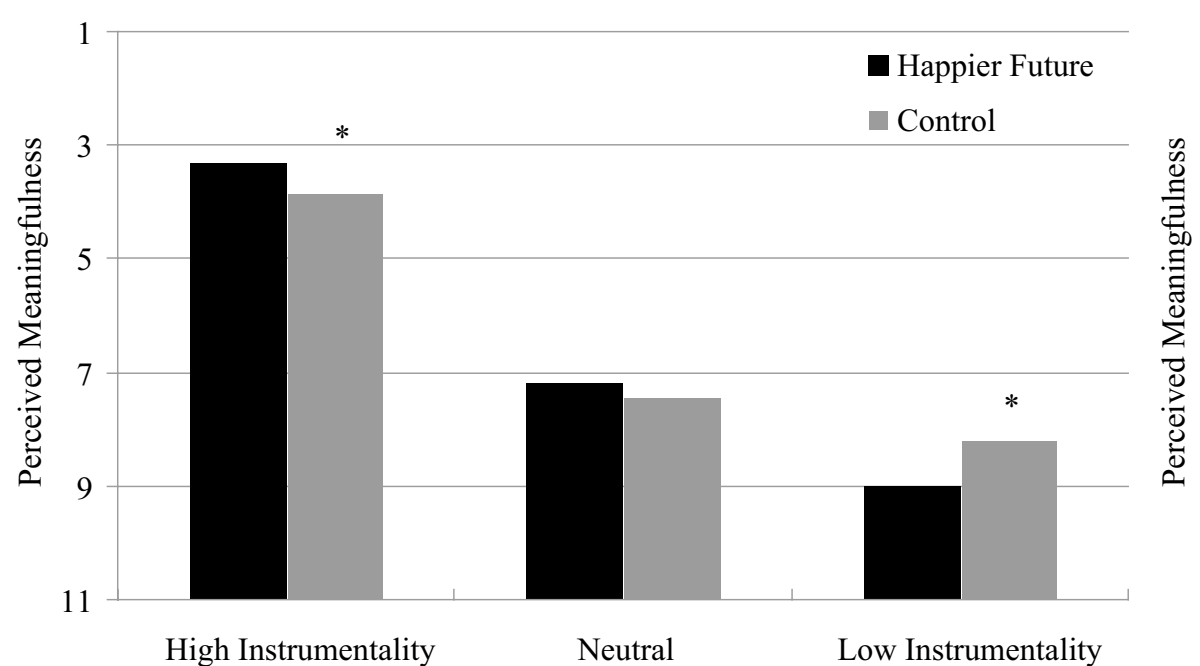

Fig. 1 Meaningfulness of Behavior Following the Future Focus Manipulation (Study 1). The ranked meaningfulness of three behavior clusters of participants who focused on future happiness relative to control condition. Lower averages indicate greater perceived meaningfulness

piness, among students, were visiting family, making friends, having a laugh, and partying, which we subsequently labeled the high instrumentality behavior cluster $(M=3.40$, $S D=.77)$. The least helpful behaviors, according to students, were saving money, watching a movie, snacking, and watching soaps on television $(M=9.40, S D=.89)$. These four behaviors were subsequently labeled the low instrumentality behavior cluster. The four remaining behaviors, exercising, attending a concert, eating healthy, and studying were ranked in between $(M=6.72, S D=1.27)$ and hence constituted our neutral behavior cluster.

At the end of each pilot study and the main study, we explained to participants the goals of each study and thanked them for their participation.

\subsubsection{Results}

Average evaluation scores were computed for each cluster with low numbers indicating greater perceived meaningfulness. The behaviors' evaluations were subjected to a repeated measure ANOVA with the forecast focus manipulation as between-subjects factor and the behavior cluster (high vs. neutral vs. low instrumentality) as within-subject factor. The results indicated no main effect of the future focus manipulation $(F<1)$, a main effect of the behaviors' cluster, $F(2,47)=335.07, p<.001, \eta^{2}=.77$, and the critical interaction, $F(2,47)=5.25, p<.01, \eta^{2}=.06$ (illustrated in Fig. 1).

The high instrumentality behavior cluster received, on average, the lowest scores (i.e. most meaningful; $M=3.59, S D=.94)$, followed by the neutral cluster $(M=7.32$, $S D=1.41)$; the highest scores were given to the low instrumentality behavior cluster $(M=8.60, S D=1.20)$. Importantly, participants who focused on a happy future scored the behaviors of the high instrumentality cluster as lower (i.e. more meaningful; $M=3.33, S D=.94)$ compared to those in the control condition $(M=3.85, S D=1.00)$, $F(1,48)=4.11, p=.05, \eta^{2}=.08$. The opposite was true for the behaviors in the low value behavior cluster which were scored higher among those who focused on a happier 
future $(M=9.00, S D=1.04)$ compared to the control condition $(M=8.20, S D=1.24)$, $F(1,48)=6.14, p=.02, \eta^{2}=.11$. No significant differences existed between the neutral behavior scores of the happier future focus condition $(M=7.18, S D=1.20)$ compared to the control condition $(M=7.45, S D=1.61 ; F<1)$.

\subsubsection{Discussion}

In the current study, we examined whether anticipated happiness yields an existential benefit. Specifically, we proposed that envisioning a happy future contributes to the perceived meaningfulness of behaviors deemed instrumental in the pursuit of this envisioned increases in happiness. Indeed, the results confirmed that those focusing on future happiness ranked behaviors as more meaningful relative to a control condition. Moreover, this increase in perceived meaningfulness did not occur for all behaviors indiscriminately, but was specific to those that were deemed highly instrumental for facilitating happiness.

These results reflect that increased happiness forecasts contribute to perceived meaningfulness of behavior, but only for behavior that serves happiness. When behavior is not instrumental for this goal, then anticipating happiness reduces the perceived meaningfulness of that behavior. The results are consistent with our assumption that happiness forecasts serve the superordinate goal of perceiving everyday life as meaningful and that people focus on activities that are instrumental for this goal. These findings are also consistent with those by King and colleagues (2006), but show how not only present but also anticipated future positive affect (here, happiness) contributes to meaning. Study 2 and 3 further tested the existential function of anticipating happiness by considering a crucial variable: search for meaning in life.

\subsection{Study 2: Search for Meaning in Life Amplifies Anticipated Happiness}

In Study 2, we tested the existential function of anticipated happiness from a different angle. Based on our reasoning that imagining a happier future can help to obtain a sense of meaning, we predicted that people who are strongly searching for meaning in life, compared to their less searching counterparts, will be particularly likely to a future replete with happiness. Thus, by conceptualizing search for meaning as a predictor, we directly examined the motivational function that search for meaning in life plays in shaping happiness anticipations.

\subsubsection{Method}

4.2.1.1 Participants and Design Eighty-seven students (24 men, 62 women, 1 unspecified; $M_{\text {age }}=24.36, S D=7.57$ ) were approached on campus and were willing to take part in the study. Post-hoc power analysis for a multiple regression analysis with three predictors indicated a power of $(1-\beta)=.88$ for an overall $R^{2}$ of .15 , assuming a two-tailed $\alpha$ of $.05{ }^{1}$

4.2.1.2 Materials and Procedure After giving informed consent and reporting demographics, participants completed the meaning in life questionnaire (Steger et al. 2006). This

\footnotetext{
1 Note that the multilevel nature of these data likely increased the power of each predictor given that each participant contributed more than 1 data-entry.
} 
measurement consists of two conceptually distinct subscales that assess people's search for meaning in life (e.g. "I am looking for something that makes my life meaningful"; $\alpha=.89$ ) and their perceived presence of meaning in life ("My life has a clear sense of purpose"; $\alpha=.88$; after recoding the reversed item). Each subscale is measured with five items that have to be rated on seven-point scales ranging from 1 (not at all) to 7 (very much). Next, we asked them to rate their current happiness with the item "On the whole, how happy would you say you are?" on a 10 point scale from 1 (totally unhappy) to 10 (totally happy). Participants rated on similar scales how happy they expected to be in 1-5 years from the present.

\subsubsection{Results and Discussion}

4.2.2.1 Expected Happiness We entered the happiness ratings in a random intercept multilevel analysis with the participant as higher level, and the six happiness ratings as lower level. Linear and quadratic effects of the target time distance of the happiness forecasts $(0$ through 5 years) were then added as fixed predictors of happiness. Importantly, we also added as fixed predictors participants' averaged search for meaning in life and the interaction between the search for meaning in life with the linear effect of time.

The analysis revealed both a significant linear effect of time distance, $\gamma=.26, S_{\mathrm{e}}=.10$, $t(509)=2.55, p=.014$, a significant quadratic effect of time distance on happiness, $\gamma=-.04, S_{\mathrm{e}}=.01, t(509)=2.55, p=.011$, and a significant effect of the search for meaning in life, $\gamma=-.32, S_{\mathrm{e}}=.11, t(509)=2.98 p=.003$. These results indicate that happiness was generally expected to increase as a function of time, and that this expected increase gradually reached a ceiling. Moreover, the search for meaning in life was associated with somewhat lower overall happiness. Importantly, however, the more participants were in search for meaning in life, the more they anticipated their happiness to increase, as signified by a significant interaction effect, $\gamma=.05, S_{\mathrm{e}}=.02, t(509)=3.47, p=.001 .^{2}$ These results imply that, as predicted, people who are searching for meaning in life imagine a brighter future compared to those less in search for meaning. Figure 2 provides a graphical illustration of these findings where the modeled expected happiness forecasts are plotted at 1 standard deviation below and above the sample's average search for meaning in life.

We conducted the same multilevel analysis as before but added the averaged presence of meaning in life scores and the presence of meaning in life $\times$ linear time distance interaction as fixed predictors of participants' happiness ratings. The results of this analysis were very similar of the previous multilevel model. A significant linear effect of the distance in time, $\gamma=.26, S_{\mathrm{e}}=.10, t(418.84)=2.56, p=.011$, and a significant quadratic effect of time distance on happiness were observed, $\gamma=-.04, S_{\mathrm{e}}=.01, t(419.18)=2.63$, $p=.009$. In addition, a significant effect of presence of meaning in life was observed, $\gamma=.80, S_{\mathrm{e}}=.16, t(114.64)=4.96, p<.001$, as well as a significant presence of meaning in life $\times$ time interaction, $\gamma=-.07, S_{\mathrm{e}}=.03, t(419.93)=2.85, p=.005$, suggesting that the more participants viewed their lives to be meaningful, the happier they were and the less they expected happiness to increase over time. Also, the effect of search for meaning in life was reliable, $\gamma=-.32, S_{\mathrm{e}}=.10, t(114.03)=3.35, p=.001$. Most importantly,

\footnotetext{
${ }^{2}$ We estimated pseudo- $R^{2}$ values for these predictors in a stepwise approach, with each model gaining in complexity: relative to the empty-model, the psudo- $R^{2}$ for the linear effect of time was, $R_{p}^{2}=.33$; time's quadratic effect (when added to the previous model) yielded, $R_{p}^{2}=.02$; meaning search gave, $R_{p}^{2}=.02$; the linear time $\times$ meaning search interaction gave, $R_{p}^{2}=.03$.
} 


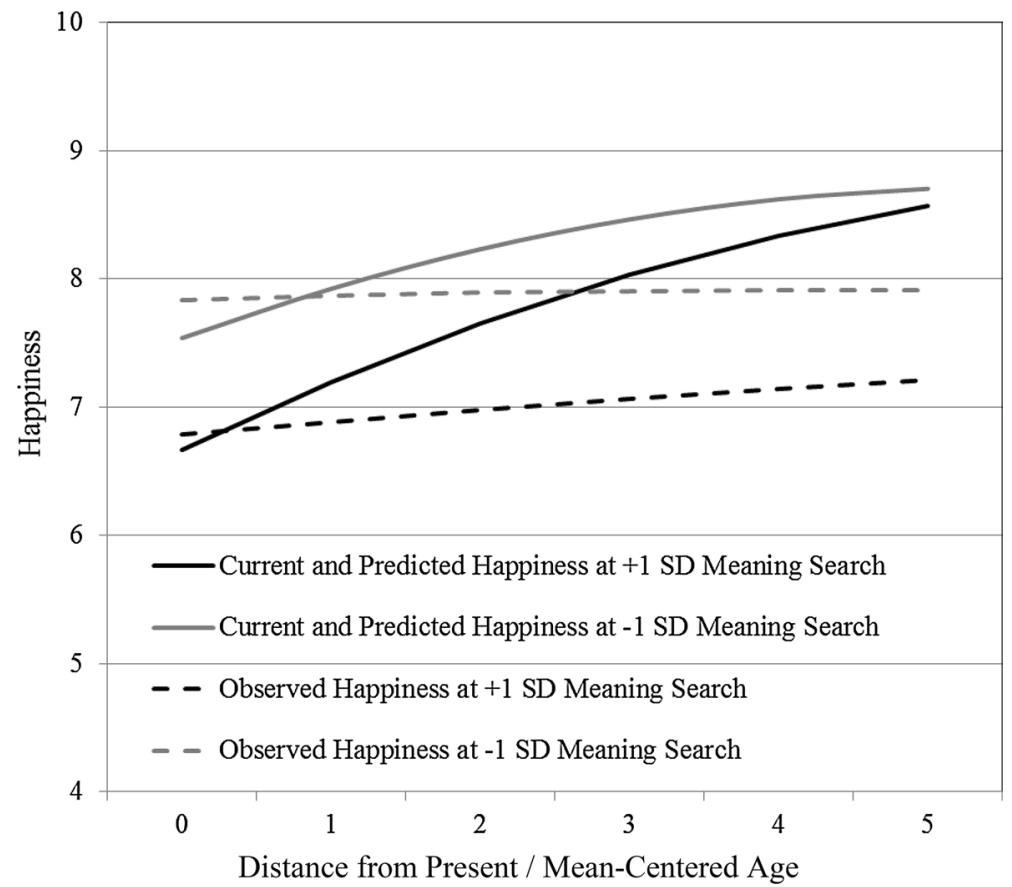

Fig. 2 Forecasted and Observed Happiness as a Function Time and the Search for Meaning in Life (Study 2). Four regression lines representing the modeled associations of real age with participants' observed happiness (between subjects effect), and the modeled increase in happiness that participants expected over 5 years (within subjects fixed effect), all plotted at one standard deviation below and above the average search for meaning in life. Note that direct comparisons between the two observed happiness lines with the two current and predicted happiness lines should be made with caution as these lines reflect estimates from different levels of analysis

however, the critical interaction between time and participants' search for meaning in life remained significant and was very similar in magnitude as in the original analysis, $\gamma=.05$, $S_{\mathrm{e}}=.01, t(418.50)=3.55, p<.001 .^{3}$

In the current study, we tested whether imagined increases in happiness serve an existential function by considering individual difference in search for meaning in life. As predicted, participants high in search for meaning in life anticipated greater happiness than other participants. In addition, the interaction between increased anticipated happiness and search for meaning in life remained significant after controlling for actual presence of perceived meaning in life. Overall, this study demonstrates that people who search for meaning in life are particularly inclined to imagine a happier future.

\footnotetext{
${ }^{3}$ We again estimated pseudo- $R^{2}$ values for these predictors in a stepwise approach, with each model gaining in complexity: relative to the empty-model, the psudo- $R^{2}$ for the linear effect of time was $R_{p}^{2}=.33$; time's quadratic effect (when added to the previous model) yielded, $R_{p}^{2}=.02$; meaning presence (when added) yielded $R_{p}^{2}=.02$; the linear time $\times$ meaning presence interaction gave $R_{p}^{2}=.02$; meaning search then yielded $R_{p}^{2}=.00$; the linear time $\times$ meaning search interaction gave $R_{p}^{2}=.03$.
} 


\subsection{Study 3: Anticipated Happiness and Meaning in Life}

In Study 3, we combined the approaches of the previous studies in order to test the existential function and benefit of anticipated happiness by both manipulating anticipated happiness and measuring people's search for meaning in life. After observing in Study 1 that a focus on a happier looming future accentuates the meaning attributed to specific behaviors, complemented by the finding from Study 2 that predictions of increased happiness become more pronounced with increasing levels of meaning search, we next examined whether people consider life to become more meaningful after imagining a happier future.

Importantly, similar to Study 2 we examined the moderating effect of search for meaning to test whether the predicted meaning boost stemming from considering a happier future is partly originating from this motivational source. We predicted that by having people focus on increasing future happiness (vs. control) subsequently increases anticipated meaning in life, especially among people high in search for meaning in life.

\subsubsection{Method}

4.3.1.1 Participants and Design Eighty-two students ( 17 men, 65 women; $M_{\text {age }}=22.17$, $S D=6.35$ ) took part in the study. Participants were randomly assigned to either a happier future focus or control condition. Post-hoc power analysis for a multiple regression analysis with three predictors indicated a power of $(1-\beta)=.91$ for an overall $R^{2}$ of .15 , assuming a two-tailed $\alpha$ of .05 .

4.3.1.2 Materials and Procedure Participants gave their informed consent and reported demographic information. After completing the search for meaning in life scale $(\alpha=.92$; Steger et al. 2006; see Study 2), they were assigned to either the happiness focus condition or the control future condition (see Study 1). After the manipulation, participants engaged in forecasting happiness and meaning in life by indicating their responses to the items "To what extent do you think that your happiness will increase in the future?" and "To what extent do you think that your perceived meaning in life will increase in the future?" on scales from 1 (not at all) to 7 (very much).

\subsubsection{Results and Discussion}

A one-way ANOVA confirmed that relative to the control condition $(M=4.78, S D=1.12)$, the focus on a happier future amplified levels of anticipated happiness $(M=5.36$, $S D=1.14), F(1,80)=5.41, p=.02, \eta^{2}=.06$. Thus, the manipulation was effective.

A multiple-regression analysis with the effect coded forecasting manipulation ( $-1=$ control, $1=$ happier future focus), the standardized search for meaning in life scores, and their interaction as predictors of meaning in life indicated a significant interaction effect, $B=.40, S_{\mathrm{e}}=.17, t(78)=2.39, p=.02$, as well as a significant partial effect of search for meaning, $B=.64, S_{\mathrm{e}}=.17, t(78)=3.90, p<.001$; the partial effect of the manipulation was not significant $(t<1)$. A simple slope analysis (Hayes and Matthes 2009) confirmed that the search for meaning in life was significantly and positively associated with anticipated meaning in life amongst those who focused on a happier future, $B=1.04$, 
Fig. 3 Anticipated Meaning in Life as a Function of Future Focus Manipulation and the Search for Meaning in Life (Study 3). Bars represent the predicted levels of anticipated happiness gains for -1 and +1 standard deviation above the mean search for meaning

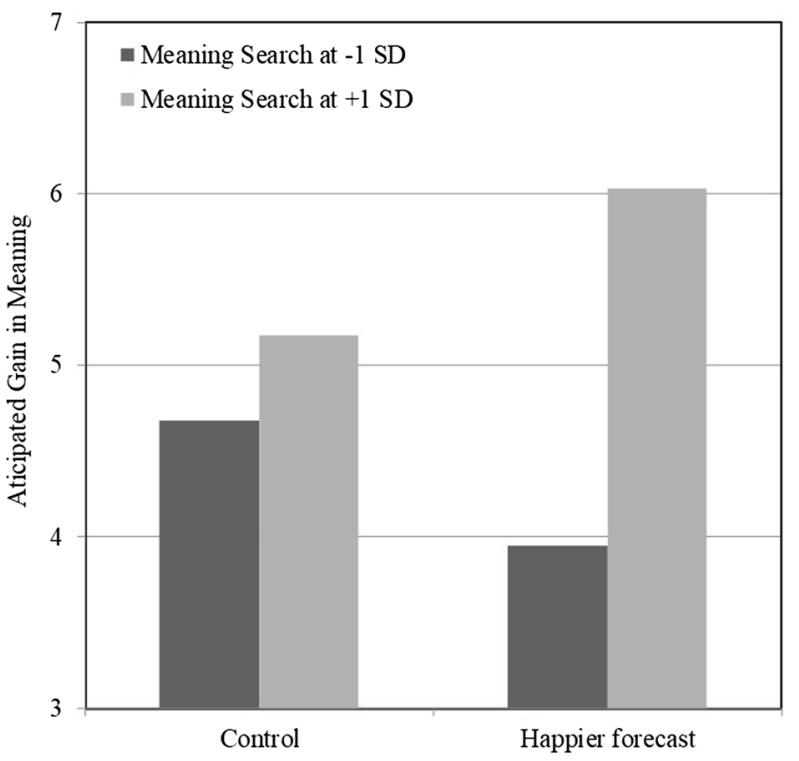

$S_{\mathrm{e}}=.22, t(78)=4.75, p<.001$, whereas no reliable association emerged for the control condition, $B=.25, S_{\mathrm{e}}=.25, t(78)=1.01, p=.32$ (Fig. 3 ). ${ }^{4}$

Overall, conceptually replicating Study 1 , the current study indicated that anticipating future happiness increases anticipated meaningfulness. Moreover, consistent with Study 2, those who are strongly searching for meaning in life used the opportunity to reflect on a happier future to make future life seem more meaningful, as opposed to people who were less searching for meaning in life. Extending Study 1 and 2, Study 3 thus shows how that the imagined increase in future happiness among those high in meaning search subsequently lends more anticipated meaning. Thus, this experiment integrates and completes the prior studies by demonstrating that anticipating a happier future yields the existential benefit of envisioning a more meaningful life, a strategy employed especially by those high in search for meaning in life.

\section{General Discussion}

People wish to be happy and many behaviors are indeed in some way directed at optimizing or increasing happiness and related qualities such as well-being and life satisfaction (e.g. Larsen and Prizmic 2004; Ryan and Deci 2000). We argued that people envision the

\footnotetext{
${ }^{4}$ Interestingly, people who imagined a happier (vs control) future (1) anticipate more happiness, and (2) subsequently anticipated a more meaningful life. This indirect effect, from imagining a happier future to perceiving more meaning in life through anticipated happiness gains, was stronger for those high in search for meaning in life. Thus, especially those searching for meaning used forecasted happiness gains as a way to imbue their life with meaning. While the results of this conditional mediation process are in line with our reasoning, we decided not to report these results given the relatively low sample size for this complex analysis. We are happy to share details with those interested.
} 
future to be brighter than the present, even though such future projections tend in reality to be biased (e.g. Brickman and Campbell 1971; Diener et al. 2006; Wilson and Gilbert 2003; Schkade and Kahneman 1998; Wilson et al. 2000). Importantly, we proposed that these anticipated increases in happiness serve an existential function by imbuing behaviors with purpose and boosting meaning in life.

We tested the existential function of anticipated happiness in a series of three studies. In Study 1, we examined the link between happiness and meaningfulness as a function of the type of behavior people engage in. Specifically, we manipulated the focus on a happier future and the instrumentality of behaviors as source of happiness. We found that having people reflect on future happiness increases made them perceived behaviors that were highly instrumental for happiness as more meaningful than in the control condition; behaviors that were not instrumental for happiness were perceived as less meaningful than in the control condition. Consistent with our hypothesis about the role of happiness, Study 2 demonstrated that people high in search for meaning in life imagined the future to be particularly happy compared to their less meaning-searching counterparts. Finally, in Study 3 we tested the relationship between happiness and meaningfulness by combining search for meaning and by examining the effect of anticipated happiness on envisioned meaning in life. The results revealed that those high in search of meaning indeed anticipate a sense of meaning in life as a result of forecasting this brighter future. This last study thus replicated and complimented Study 1 and Study 2 by examining the process through which people who search for meaning use anticipated happiness to imbue life with the anticipated meaning they seek. Overall, these studies indicate that imagining a brighter future yields an important existential benefit: It serves as a strategy to find meaning in life.

\subsection{Implication and Future Directions}

In recent years, the importance of viewing life as meaningful and the far-reaching implications of the pursuit of meaning have been documented in many studies (see Greenberg et al. 2004; Steger et al. 2006). For example, threats to appraising life or behaviors as meaningful trigger the detection of patterns and structure (Proulx and Heine 2006), the derogation of outgroups (Van Tilburg and Igou 2011b), and the protection or valuation of cultural symbols (McGregor et al. 1998; Van Tilburg and Igou 2011a), just to name a few.

In the current research, we examined the dynamic interaction between the presence and search for meaning in life with current and anticipated happiness. Although happiness and meaning are associated with each other and may both be considered necessary ingredients to achieve a general sense of well-being (Steger et al. 2006), it is important to stress that happiness and meaning are distinct psychological experiences (e.g. Heintzelman and King 2014), on conceptual as well as empirically levels of analysis. This argument is particularly well articulated by Baumeister and colleagues (2013). These authors suggest that whereas happiness, at least in its fundamental form, is associated with the satisfactory of needs and wants, meaning can be derived from more cognitively and emotional complex processes such as the identification of a significant, and not yet satisfied, purpose. They illustrate this with the example of an oppressed political activist, who is unhappy with life as it is, but nonetheless finds meaning in anticipated future changes. Indeed, happiness and meaning are also empirically distinct. For example, Baumeister and colleagues (2013) found that meaningfulness was more strongly characterized by other-benefitting intentions such as buying gifts and waiting for others than happiness. Thus, albeit interrelated, happiness and meaning are distinct psychological experiences. 
We proposed that the anticipation of happiness may serve the distinct experience of meaning in life. We examined this assumption from an existential psychological perspective. Future research should specify whether for people who value happiness more than others the relationship is stronger than for people who focus less on happiness. This differentiation touches on distinctions between hedonists versus non-hedonist, hedonic versus eudaimonic well-being or subjective versus psychological well-being (e.g. Keyes et al. 2002; Fredrickson et al. 2013, 2015). For example, for non-hedonists the predictive value of happiness for meaning in life is likely to be lower than for hedonists. Certainly, with hedonism serving as a source of meaning, in particular for some people within a given culture, differences between cultures are likely (e.g. Hofstede et al. 2010). We have not examined such moderating influences, however, we suspect that they exist and suggest that future research addresses these issues.

Besides potential cultural differences, is it likely that individual differences moderate the effect we report. For example, people who are high in neuroticism tend to anticipate more negative emotional responses to future events, and extraverts instead tend to anticipate more positive affective responses (Hoerger and Quirk 2010). This raises the possibility that people high in neuroticism and extraversion may forecast less and more happiness gains, respectively. Considering one's future is therefore likely to lend less perceived meaning to those high in neuroticism whereas the opposite can be predicted for those high in extraversion. Likewise, the individual circumstances that people go through in life will likely affect the strength of the association between anticipated happiness and meaning in life (e.g. across stressful and non-stressful events; Shmotkin and Shrira 2013) and the tendency to forecast a happier future in general. People who suffer from depression, for example, tend to anticipate a bleaker future because they use their affective state in the present as proxy for that in the future (Marroquín and Nolen-Hoeksema 2015). Likely, these people do not gain the perceived meaning from envisioning their future as the people in our studies did. Examining individual differences and variations in personal circumstances will further enhance our understanding of the link between forecasted happiness and perceptions of meaning in behavior and life.

A common denominator across many behaviors directed at protecting or establishing meaning is that they typically involve the increased adherence to or bolstering of worldviews, ideologies, and values available in the present (e.g. Heine et al. 2006). The findings from the current investigation suggest that meaning can also be found or derived through envisioning the future. Our research thus adds to the study of meaning that perspectives of the future are harnessed by people in the attempt to imbue everyday behavior with meaning. Possibly, people who have particular difficulty in perceiving their current life as meaningful, for example in the face of temporary adversity such as job loss or trauma, may find meaning again in their activities by focusing on a potentially brighter future.

People are, on average, overly optimistic about state of their future affect (Wilson and Gilbert 2003). Besides this general optimistic trend, it is possible that individuals higher in dispositional optimism are particularly prone to anticipate a brighter future. Individual differences in optimism correlate with factors such as life satisfaction (Jovanovic and Gavrilov-Jerkovic 2013) and lower stress (Pacheco and Kamble 2016) in the present, as well as the over-anticipation of future fortunate events (Radcliffe and Klein 2002; Weinstein 1980). As mentioned earlier, a limitation of the current research is that we did not assess and control for individual differences in optimism. Steger and colleagues (2006) did not find a significant correlation between search for meaning in life and optimism, but they did find a moderately positive significant correlation between perceived presence of 
meaning in life and optimism. Future research will do well to include optimism as additional variable to test the robustness of our results after controlling for this important variable.

Future research should address a role of search for meaning in life that we did not examine in our studies. Possibly, the effect of anticipated happiness on perceived meaning of specific behaviors is moderated by meaning search. In line with our approach, we would expect that for people with higher (vs. lower) levels of search for meaning the impact of anticipated happiness on perceived meaningfulness of specific behaviors ought to be stronger.

Another limitation of our research is its cultural boundaries. In Study 1, we examined the perceived meaningfulness of specific behaviors that were ranked as more or less instrumental to future happiness within a student population. The purpose of Study 1 was to investigate if the instrumentality towards happiness that these specific behaviors represented mattered in people's judgements of their meaningfulness. Would members of different populations (e.g. non-European or American cultures) judge these behaviors similarly meaningful as in Study 1? If so, would these behaviors be rated differently in their instrumentality? Accordingly, it is possible that other behaviors are seen as more meaningful when people forecast a brighter future. Essentially, envisioning a happier future should increase the perceived meaningfulness of behaviors instrumental towards that future state, and which behaviors those are will naturally depend on cultural and individual characteristics. Future research should examine if culture or individual differences moderate these effects and if this moderation affects which behaviors are seen as more or less instrumental.

Future happiness is not the only source of meaning within processes of 'mental time travelling'. Research indicates that people benefit from a particular view of the past: nostalgic reverie, especially when confronted with threats to perceived meaning in life, such as mortality salience (Juhl et al. 2010; Routledge et al. 2006) or boredom (Van Tilburg and Igou 2012, 2016). Nostalgia is triggered by the desire to find meaning and it increases the perceived meaning of life (e.g. Routledge et al. 2011; Sedikides et al. 2004; Van Tilburg et al. 2013; Wildschut et al. 2006). Together, the current study of happiness forecasts and earlier findings on nostalgic evocation suggest that the repertoire available to those who seek to find meaning surpasses the presence; it encompasses the past and the future.

\subsection{Is ignorance bliss?}

It does not come as a surprise that people are biased when making predictions about their lives (e.g. Wilson and Gilbert 2003). Going beyond this notion, our studies show that potentially unrealistic predictions of happiness gains instill meaning in people's lives. Our findings thus raise the question of whether or not people should be discouraged to hold unrealistically biased expectations of the future, or that they should continue to "dream on.' People may spend years of their lives pursuing a dream that will never come true, with the risk of bitter realization that their past pursuit of happiness was largely in vain. It is important to note, however, that the current research did not address how the engagement in meaningful behavior in turn affects happiness. Possibly, a lack of perceived meaning in our activities leaves us more unhappy, and maintaining the illusion of a brighter future may thus help us to at least prevent things from getting any worse.

Research in the domain of existential psychology suggests that adhering to religion, psychologically defined in-groups, or cultural believes helps people maintain the view that life has some greater purpose or meaning (e.g. Heine et al. 2006). People who fail to establish the view that life is meaningful are at greater risk of depression, suicidal ideation, and 
committing suicide. Perhaps the anticipation of increases in happiness offers an alternative to the abovementioned sources of meaning, though it is evident that the question of whether or not the likely false belief that the future will bring greater happiness should be discouraged is very complex. Nevertheless, the current findings present important novel insights into the process by which people attain a sense of meaning and purpose in their behaviors motivated by the overly hopeful believe of a happier future.

\section{Compliance with Ethical Standards}

Conflict of interest The authors declare that there are no potential conflicts of interest with respect to the research, authorship, and/or publication of this article.

Ethical Approval All procedures performed in studies involving human participants were in accordance with the ethical standards of the institutional research committee and with the 1964 Helsinki declaration and its later amendments or comparable ethical standards.

Informed Consent Informed consent was obtained from all individual participants included in the study.

Open Access This article is distributed under the terms of the Creative Commons Attribution 4.0 International License (http://creativecommons.org/licenses/by/4.0/), which permits unrestricted use, distribution, and reproduction in any medium, provided you give appropriate credit to the original author(s) and the source, provide a link to the Creative Commons license, and indicate if changes were made.

\section{References}

Baumeister, R. F., Vohs, K. D., Aaker, J. L., \& Garbinsky, E. N. (2013). Some key differences between a happy life and a meaningful life. Journal of Positive Psychology, 8, 505-516. https://doi.org/10.1080 $/ 17439760.2013 .830764$.

Blanchflower, D. G., \& Oswald, A. J. (2004). Well-being over time in Britain and the USA. Journal of Public Economics, 88, 1359-1386. https://doi.org/10.1016/s0047-2727(02)00168-8.

Bonebright, C. A., Clay, D. L., \& Ankenmann, R. D. (2000). The relationship of workaholism with worklife conflict, life satisfaction, and purpose in life. Journal of Counseling Psychology, 47, 469-477. http s://doi.org/10.1037/0022-0167.47.4.469.

Brickman, P., \& Campbell, D. T. (1971). Hedonic relativism and planning the good society. In M. H. Appley (Ed.), Adaptation level theory: Symposium (pp. 287-302). New York, NY: Academic Press.

Brickman, P., Coates, D., \& Janoff-Bulman, R. (1978). Lottery winners and accident victims: Is happiness relative? Journal of Personality and Social Psychology, 36, 917-927. https://doi.org/10.1037/0022 -3514.36.8.917.

Buehler, R., \& McFarland, C. (2001). Intensity bias in affective forecasting: The role of temporal focus. Personality and Social Psychology Bulletin, 27, 1480-1493. https://doi.org/10.1177/01461672012711009.

Busseri, M. A., Choma, B., \& Sadava, S. W. (2008). Functional or fantasy? Examining the implications of subjective temporal perspective "trajectories" for life satisfaction. Personality and Social Psychology Bulletin, 35, 295-308. https://doi.org/10.1177/0146167208327215.

Deci, E. L., \& Ryan, R. M. (2000). The "what" and "why" of goal pursuits: Human needs and the selfdetermination of behavior. Psychological Inquiry, 11, 227-268. https://doi.org/10.1207/s15327965pli 1104_01.

Deeg, D. J. H., \& Van Zonneveld, R. J. (1989). Does happiness lengthen life? The prediction of longevity in the elderly. In R. Veenhoven (Ed.), How harmful is happiness? Consequences of enjoying life or not (pp. 29-34). Rotterdam, the Netherlands: Universitaire Pers Rotterdam.

Diener, E. (2000). Subjective well-being: The science of happiness and a proposal for a national index. American Psychologist, 55, 34-43. https://doi.org/10.1037/0003-066x.55.1.34.

Diener, E., \& Diener, C. (1996). Most people are happy. Psychological Science, 7, 181-185. https://doi. org/10.1111/j.1467-9280.1996.tb00354.x. 
Diener, E., Lucas, R. E., \& Scollon, C. N. (2006). Beyond the hedonic treadmill: Revising the adaptation theory of well-being. American Psychologist, 61, 305-314. https://doi.org/10.1037/0003-066x 61.4.305.

Fredrickson, B. L., Grewen, K. M., Algoe, S. B., Firestine, A. M., Arevalo, J. M. G., Ma, J., et al. (2015). Psychological well-being and the human conserved transcriptional response to adversity. PLoS ONE. https://doi.org/10.1371/journal.pone.0121839.

Fredrickson, B. L., Grewen, K. M., Coffey, K. A., Algoe, S. B., Firestine, A. M., Arevalo, J. M. G., et al. (2013). A functional genomic perspective on human well-being. Proceedings of the National Academy of Science, 110, 13684-13689. https://doi.org/10.1073/pnas.1305419110.

Gilbert, D. T., Pinel, E. C., Wilson, T. D., Blumberg, S. J., \& Wheatley, T. P. (1998). Immune neglect: A source of durability bias in affective forecasting. Journal of Personality and Social Psychology, 75, 617-638. https://doi.org/10.1037/0022-3514.75.3.617.

Greenberg, J., Koole, S. L., \& Pyszczynski, T. (2004). Handbook of experimental existential psychology. New York, NY: Guilford Press.

Greenberg, J., Pyszczynski, T., \& Solomon, S. (1986). The causes and consequences of a need for selfesteem: A terror management theory. In R. F. Baumeister (Ed.), Public self and private self (pp. 189212). New York, NY: Springer.

Hayes, A. F., \& Matthes, J. (2009). Computational procedures for probing interactions in OLS and logistic regression: SPSS and SAS implementations. Behavior Research Methods, 41, 924-936. https://doi. org/10.3758/brm.41.3.924.

Heckhausen, J., \& Heckhausen, H. (2008). Motivation and action. New York, NY: Cambridge University Press.

Heine, S. J., Proulx, T., \& Vohs, K. D. (2006). The meaning maintenance model: On the coherence of social motivations. Personality and Social Psychology Review, 10, 88-110. https://doi.org/10.1207/s1532795 7pspr1002_1.

Heintzelman, S. J., \& King, L. A. (2014). (The feeling of) meaning-as-information. Personality and Social Psychology Review, 8, 153-167. https://doi.org/10.1177/1088868313518487.

Heller, D., Stephan, E., Kifer, Y., \& Sedikides, C. (2011). What will I be? The role of temporal perspective in predictions of affect, traits, and self-narratives. Journal of Experimental Social Psychology, 47, 610-615. https://doi.org/10.1016/j.jesp.2011.01.010.

Hicks, J. A., Schlegel, R. J., \& King, L. A. (2010). Social threats, happiness, and the dynamics of meaning in life judgments. Personality and Social Psychology Bulletin, 36, 1305-1317. https://doi.org/10.1177 /0146167210381650.

Hoerger, M., \& Quirk, S. W. (2010). Affective forecasting and the Big Five. Personality and Individual Differences, 49, 972-976. https://doi.org/10.1016/j.paid.2010.08.007.

Hofstede, G., Hofstede, G. J., \& Minkov, M. (2010). Cultures and organizations: Software of the mind. New York, NY: McGraw-Hill Professional.

Igou, E. R. (2004). Lay theories in affective forecasting: The progression of affect. Journal of Experimental Social Psychology, 40, 528-534. https://doi.org/10.1016/j.jesp.2003.09.004.

Igou, E. R. (2008). "How long will I suffer?" versus "How long will you suffer?" A self-other effect in affective forecasting. Journal of Personality and Social Psychology, 95, 899-917. https://doi.org/10.1037/ a0011619.

Jovanovic, V., \& Gavrilov-Jerkovic, V. (2013). Dimensionality and validity of the Serbian version of the life orientation test-revised in a sample of youths. Journal of Happiness Studies, 14, 771-782. https://doi. org/10.1007/s10902-012-9354-2.

Juhl, J., Routledge, C., Arndt, J., Sedikides, C., \& Wildschut, T. (2010). Fighting the future with the past: Nostalgia buffers existential threat. Journal of Research in Personality, 44, 309-314. https://doi. org/10.1016/j.jrp.2010.02.006.

Kahneman, D., Slovic, P., \& Tversky, A. (1982). Judgment under uncertainty: Heuristics and biases. New York, NY: Cambridge University Press.

Keyes, C. L. M., Shmotkin, D., \& Ryff, C. D. (2002). Optimizing well-being: The empirical encounter of two traditions. Journal of Personality and Social Psychology, 82, 1007-1022. https://doi.org/10.1037 //0022-3514.82.6.1007.

Kim, J., Kang, P., \& Choi, I. (2014). Pleasure now, meaning later: Temporal dynamics between pleasure and meaning. Journal of Experimental Social Psychology, 55, 262-270. https://doi.org/10.1016/j.jesp.2014 .07 .018 .

King, L. A., Hicks, J. A., Krull, J. L., \& Del Gaiso, A. K. (2006). Positive affect and the experience of meaning in life. Journal of Personality and Social Psychology, 90, 169-179. https://doi.org/10.1037 /0022-3514.90.1.179. 
Kruglanski, A. W., Shah, J., Fishbach, A., Friedman, R., Chun, W. Y., \& Sleeth-Keppler, D. (2002). A theory of goal systems. In M. Zanna (Ed.), Advances in experimental social psychology (Vol. 34, pp. 331-376). New York, NY: Academic Press.

Larsen, R. J., \& Prizmic, Z. (2004). Affect regulation. In R. F. Baumeister \& K. D. Vohs (Eds.), Handbook of self-regulation: Research, theory, and applications (pp. 40-61). New York, NY: The Guilford Press.

Loewenstein, G. F., \& Schkade, D. (1999). Wouldn't it be nice? Predicting future feelings. In D. Kahneman, E. Diener, \& N. Schwartz (Eds.), Well-being: The foundations of hedonic psychology (pp. 85-105). New York, NY: Russell Sage Foundation.

Maher, P., Van Tilburg, W. A. P., \& Van den Tol, A. J. M. (2013). Meaning in music: Deviations from expectations in music prompt outgroup derogation. European Journal of Social Psychology, 43, 449454. https://doi.org/10.1002/ejsp.1969.

Marroquín, B., \& Nolen-Hoeksema, S. (2015). Event prediction and affective forecasting in depressive cognition: Using emotion as information about the future. Journal of Social and Clinical Psychology, 34, 117-134. https://doi.org/10.1521/jscp.2015.34.2.117.

McGregor, H. A., Lieberman, J. D., Greenberg, J., Solomon, S., Arndt, J., Simon, L., et al. (1998). Terror management and aggression: Evidence that mortality salience motivates aggression against worldviewthreatening others. Journal of Personality and Social Psychology, 74, 590-605. https://doi.org/10.1037 /0022-3514.74.3.590.

Moynihan, A. B., Van Tilburg, W. A. P., Igou, E. R., Wisman, A., Donnelly, A. E., \& Mulcaire, J. B. (2015). Eaten up by boredom: Consuming food to escape awareness of the bored self. Frontiers in Psychology. https://doi.org/10.3389/fpsyg.2015.00369.

Mroczek, D. K., \& Kolarz, C. M. (1998). The effect of age on positive and negative affect: A developmental perspective on happiness. Journal of Personality and Social Psychology, 75, 1333-1349. https://doi. org/10.1037/0022-3514.75.5.1333.

Pacheco, B., \& Kamble, S. V. (2016). The role of optimism in stress and coping of undergraduate students in Goa. The International Journal of Indian Psychology, 3, 60-68. http://www.ijip.in/index.php/?view $=$ article \&id $=243$

Pannells, T. C., \& Claxton, A. F. (2008). Happiness, creative ideation, and locus of control. Creativity Research Journal, 20, 67-71. https://doi.org/10.1080/10400410701842029.

Peterson, C., Park, N., \& Seligman, M. E. P. (2005). Orientations to happiness and life satisfaction: The full life versus the empty life. Journal of Happiness Studies, 6, 25-41. https://doi.org/10.1007/s10902-0041278-z.

Post, S. G. (2005). Altruism, happiness, and health: It's good to be good. International Journal of Behavioral Medicine, 12, 66-77. https://doi.org/10.1207/s15327558ijbm1202_4.

Proulx, T., \& Heine, S. J. (2006). Death and black diamonds: Meaning, mortality, and the meaning maintenance model. Psychological Inquiry, 17, 309-318. https://doi.org/10.1080/10478400701366985.

Radcliffe, N. M., \& Klein, W. M. P. (2002). Dispositional, unrealistic, and comparative optimism: Differential relations with the knowledge and processing of risk information and beliefs about personal risk. Personality and Social Psychology Bulletin, 28, 836-846. https://doi.org/10.1177/0146167202289012.

Robinson, M. D., \& Ryff, C. D. (1999). The role of self-deception in perceptions of past, present, and future happiness. Personality and Social Psychology Bulletin, 25, 596-608. https://doi.org/10.1177/01461672 99025005005.

Routledge, C., Arndt, J., Sedikides, C., \& Wildschut, T. (2006). A blast from the past: The terror management function of nostalgia. Journal of Experimental Social Psychology, 44, 132-140. https://doi. org/10.1016/j.jesp.2006.11.001.

Routledge, C., Arndt, J., Wildschut, T., Sedikides, C., Hart, C. M., Juhl, J., et al. (2011). The past makes the present meaningful: Nostalgia as an existential resource. Journal of Personality and Social Psychology, 101, 638-653. https://doi.org/10.1037/a0024292.

Ryan, R. M., \& Deci, E. L. (2000). Self-determination theory and the facilitation of intrinsic motivation, social development, and well-being. American Psychologist, 55, 68-78. https://doi.org/10.1037/0003 $-066 x .55 .1 .68$.

Ryan, R. M., \& Deci, E. L. (2004). Autonomy is no illusion: Self-determination theory and the empirical study of authenticity, awareness, and will. In J. Greenberg, S. L. Koole, \& T. Pyszczynski (Eds.), Handbook of experimental existential psychology (pp. 449-479). New York, NY: Guilford Press.

Schkade, D. A., \& Kahneman, D. (1998). Does living in California make people happy? A focusing illusion in judgments of life satisfaction. Psychological Science, 9, 340-346. https://doi.org/10.1111/1467 -9280.00066 .

Sedikides, C., Wildschut, T., \& Baden, D. (2004). Nostalgia: Conceptual issues and existential functions. In J. Greenberg, S. L. Koole, \& T. Pyszczynski (Eds.), Handbook of experimental existential psychology (pp. 200-214). New York, NY: Guilford Press. 
Seligman, M. E. P., Steen, T. A., Park, N., \& Peterson, C. (2005). Positive psychology progress: Empirical validation of interventions. American Psychologist, 60, 410-421. https://doi.org/10.1037/0003-066x .60.5.410.

Shmotkin, D., \& Shrira, A. (2013). Subjective well-being and meaning in life in a hostile world: Proposing a configurative perspective. In J. A. Hicks \& C. Routledge (Eds.), The experience of meaning in life: Classical perspectives, emerging themes, and controversies (pp. 77-86). New York, NY: Springer.

Steger, M. F., Frazier, P., Oishi, S., \& Kaler, M. (2006). The meaning in life questionnaire: Assessing the presence of and search for meaning in life. Journal of Counseling Psychology, 53, 80-93. https://doi. org/10.1037/0022-0167.53.1.80.

Trope, Y., Igou, E. R., \& Burke, C. T. (2006). Mood as resource in structuring goal pursuit. In J. P. Forgas (Ed.), Affect in social thinking and behavior (pp. 217-234). New York: Psychology Press. ISBN-10:1841694541.

Van Tilburg, W. A. P., \& Igou, E. R. (2011a). On the meaningfulness of existence: When life salience boosts adherence to worldviews. European Journal of Social Psychology, 41, 740-750. https://doi. org/10.1002/ejsp.819.

Van Tilburg, W. A. P., \& Igou, E. R. (2011b). On boredom and social identity: A pragmatic meaning-regulation approach. Personality and Social Psychology Bulletin, 37, 1679-1691. https://doi.org/10.1177 /0146167211418530.

Van Tilburg, W. A. P., \& Igou, E. R. (2012). On boredom: Lack of challenge and meaning as distinct boredom experiences. Motivation and Emotion, 36, 181-194. https://doi.org/10.1007/s11031-011-9234-9.

Van Tilburg, W. A. P., \& Igou, E. R. (2013a). On the meaningfulness of behavior: An expectancy x value approach. Motivation and Emotion, 37, 373-388. https://doi.org/10.1007/s11031-012-9316-3.

Van Tilburg, W. A. P., \& Igou, E. R. (2013b). De zin van een verveeld bestaan [The purpose of a boring existence]. In-Mind Nederland, 1. http://nl.in-mind.org/uploads/In-mind\%20NL/Issue\%201/VanTilbu rg\&Igou_Opgemaakt.pdf.

Van Tilburg, W. A. P., \& Igou, E. R. (2016). Going to political extremes in response to boredom. European Journal of Social Psychology, 46, 687-699. https://doi.org/10.1002/ejsp.2205.

Van Tilburg, W. A. P., \& Igou, E. R. (2017). Can boredom help? Increased prosocial intentions in response to boredom. Self and Identity, 16, 82-96. https://doi.org/10.1080/15298868.2016.1218925.

Van Tilburg, W. A. P., Igou, E. R., \& Sedikides, C. (2013). In search of meaningfulness: Using nostalgia as an antidote to boredom. Emotion, 13, 450-461. https://doi.org/10.1037/a0030442.

Weinstein, N. D. (1980). Unrealistic optimism about future life events. Journal of Personality and Social Psychology, 39, 806-820. https://doi.org/10.1037/0022-3514.39.5.806.

Weinstein, N. D., \& Lachendro, E. (1982). Egocentrism as a source of unrealistic optimism. Personality and Social Psychology Bulletin, 8, 195-200. https://doi.org/10.1177/0146167282082002.

Wildschut, T., Sedikides, C., Arndt, J., \& Routledge, C. (2006). Nostalgia: Content, triggers, functions. Journal of Personality and Social Psychology, 91, 975-993. https://doi.org/10.1037/0022-3514 91.5.975

Wilson, T. D., \& Gilbert, D. T. (2003). Affective forecasting. In M. P. Zanna (Ed.), Advances in experimental social psychology (Vol. 35, pp. 345-411). San Diego, CA: Academic Press.

Wilson, T. D., Wheatley, T., Meyers, J., Gilbert, D. T., \& Axsom, D. (2000). Focalism: A source of durability bias in affective forecasting. Journal of Personality and Social Psychology, 78, 821-836. https:// doi.org/10.1037/0022-3514.78.5.821.

Wisman, A. (2006). Digging in terror management theory: To 'use' or 'lose' the symbolic self? Psychological Inquiry, 17, 319-327. https://doi.org/10.1080/10478400701369468. 